\title{
Importance of Price for Buying Environmentally Friendly Products
}

\author{
Kamyar Kianpour*, Ahmad Jusoh, Maryam Asghari \\ Universiti Teknologi Malaysia, Malaysia \\ *kamyar_wkf@yahoo.com
}

\begin{abstract}
This study considered price as an important indicator, which could affects customers' decisionmaking about buying an environmentally friendly product and investigated the intention of buyers for buying ecological product in comparison with non-environmentally friendly products with regard to price. For such a reason products have been categorized in three different categories such as: Short term, Middle term and Long-term products. The respondents were asked to answer whether they are interested to buy environmentally friendly products when the normal products exist in the market or they have no intention to buy these kinds of products. More over it has been tried to explore that how much the buyers will accept to pay more for environmentally friendly products rather than nonecological products in each category (short term, middle term and long term). Consequently, each category has been divided to six different percentage levels of price to indicate the percentage of acceptance by customers to pay more for the specified categories of eco-friendly products in comparison to non-environmentally friendly products. The result of this research shows that the majority of customers agree to pay certain percentage more to buy environmentally friendly products with eco labels and ecological characteristics rather than non-environmentally products when these green products are available in the market.
\end{abstract}

Keywords: Importance of price, Environmental friendly products, Green products, Ecological products

\section{Introduction}

Along with climate change, population growth and diminishing the natural resources in current era, new technologies, techniques and methods are used for producing goods, which are less energy consumption, more compatible with environment and harmless for nature and humankind. Larocheet al., (2001) express that purchasing behavior has a direct impact on producing ecologically compatible products. Increasing number of people who are willing to pay more for these kinds of products is the evidence, which supports the growth of environmentally friendly products. With regard to increasing demand for buying environmentally friendly products many companies also are producing and replacing green products with non-environmental friendly products. Shifting from normal products to environmentally friendly needs vast market research by producers. The aim of this research is to collect comprehensive knowledge on customers' willingness to buy environmentally friendly products and to find out that how much these customers accept to pay more for such products. For doing so, the customers were asked regarding acceptance of choosing environmentally friendly products with higher prices. It is useful for the firms and companies to know that how much a customer will pay for different kind of green products. This will help them to estimate their costs for producing such a product and make a business plan for gaining more market share and more profit beside preventing hazardous impacts of climate change and global warming.

\section{Literature Review}

During the time many researches has been done related to the motivators and factors that impact buyers' willingness to buy normal and even green products. Zimmer et al. (1994)in an empirical research emphasized that environmental concern is a major factor in the consumer decision making. Accordingly, studies have found positive correlations between environmental concern (i.e. attitude) and environmental friendly behavior (Roberts and Bacon, 1997). However, Hume (1991) has a different finding about the relationship between the positive attitude of consumers on the environment and their purchasing decision. He concluded that consumers do not always act in accordance with their social reporting about the environment. He says, "What people think is good idea, does not always predict what they actually do, especially in the case of environmental values and behaviors." Another assumption for buying behavior regarding environmentally friendly products is: clients who have been influenced by environmental rules and principles would purchase green products. In 2009, a survey conducted among Portuguese as the respondents, the result shows that despite their support for policies designed to 
improve the environment, their support could not translate into actions: they rarely join environmentalist associations and they do not take part in policy-making. Their participation is often based on protecting the environment by saving electricity and water, which shows that these concerns may be more closely related with economic factors than with an environmental consciousness (Paço and Raposo, 2009). According to the mentioned researches, the most important factor, which influences customers purchasing decision-making, is the economic factors and directly depends on the price of a product. Brucks et al. (2000) conduct a research to examine how key marketing variables affect consumers' judgment processes. They consider price as a key marketing variable along with brand name and product attributes. Since success of a product heavily depends on the buying pattern (behavior) of the consumers, then if the price of a product increases, the perception generally is that the buying rates will decline in the future. Normally consumers use past price levels and other context variables for a specific product in order to form a reference price to judge about the current actual product price. The experimental models consider that deviation between the actual and the reference price of a product shows utility and thus will influence consumer-purchasing behavior (Kalwani et al., 1990). Jacoby and Olson (1977) have proposed a framework for examining psychological response to price. However, classifying that concept or measuring it, in categories of mentioned framework is not always completely clear. Specifically, the stages of organizing perceptions of prices, and shaping attitudes regarding prices are usually similar indistinctly. For instance, when concepts like "price acceptability" or "perceived value for the money" are categorized as attitudinal actions, they share common concepts like "perceived savings" as perceptual response. In both cases, the consumers judge about the given price comparatively with the other prices (i.e., saving in connection to previous or common prices; "value for money" declares more standards of comparison).

The result of a survey in 1989 has shown that 67 percent of Americans agreed to pay more up to 5 to 10 percent for buying ecologically compatible products (Coddington, 1990). Another research (Suchard and Polonski, 1991) conducted on individuals who were environmentally conscious. Respondents of this research announced their willingness about paying up to 15 to 20 percent more than normal price for green products. One more survey has been conducted by mail in UK on the female consumers to examine their opinion about "environmental claims on the packaging of clothes detergents". The result has shown that 79 percent of the respondents agreed to pay more up to 40 percent for buying that specific product with any choice of brand which is identified and proven to be green (Murray and Schlacter 1990). Nagy (2004-2005) examined why consumers do not purchase environmentally friendly products. Regarding this question he ranked seven factors those avoid costumers for buying environmentally friendly products. He indicated that higher price of environmentally friendly products is the first reason that de motivates the customers for buying of these products. Nash (2002) in his paper stated that "even when consumers profess strong support for environmental protection, they are still extremely price sensitive when it comes to buying green. Indeed, a perception among King County, Washington residents that recycled-content products are more expensive was a barrier for them in purchasing these products". Kotchen (2004) provided a theoretical foundation for understanding "how demand for green products and demand for environmental quality have been influenced by market price as most important factor as well as green-demand for green production technologies, and ambient environmental quality". Many researchers examined price on specific goods, this study has been tried to segment all products in three different categories based on their life cycle. Considering discussion in this literature review, the hypotheses of this study are as follows:

- Hypothesis 1: Customers still buy a long-term environmental friendly product rather than normal product when the price increases more than a certain percentage.

- Hypothesis 2: Customers still buy a middle term environmental friendly product rather than normal product when the price increases more than a certain percentage.

- Hypothesis 3: Customers still buy a short-term environmental friendly product rather than normal product when the price increases more than a certain percentage.

\section{Methodology}

The method and measuring instrument, which are applied in this research for the collection and gathering of the data, consist of questionnaire. The questionnaire for this research has built according to the hypotheses, which are determined in the literature review. Since this study is going to generalize the idea and the result, so the population of the respondents should not just belong to one nationality. Therefore, the researcher decided to target the international postgraduate students of Universiti Teknologi Malaysia (UTM). According to the different methods of sampling and considering the two main elements (characteristics of population and objectives of this study), the author has decided to choose 
stratified sampling technique in data collection. Stratified sampling has been used when it is needed to have representatives from each subgroup of the population in the sample. Accordingly, for this research the entire population for this study is equal to whole number of international postgraduate students of all faculties in the university, which have different distribution of population. Different faculties' students will form the subgroups of stratified sampling. The sampling size will be determined based on the Krejcie and Morgan (1970) sampling method. The Confidence Level of 95\% with margin error of $5 \%$ has been considered. There are 21 faculties in this university and 8542 students are studding in postgraduate level in Universiti teknologi Malaysia. According to the method of sampling which mentioned above, the sample size of 367 students has been selected for distributing the questionnaire from different faculties. A pilot test has been done among the respondents (10\% of sample size) for validity and reliability of the survey. The questioners were distributed among 37 numbers of postgraduate students from all determined faculties. The pilot test has shown that the questionnaires were able to measure what it was supposed to measure, which means that it was valid. For reliability, the Cronbach's Alpha has been used and the reliability percentage for this questioner was 0.842 that is more than 0.7 and is completely acceptable while the numbers of variables are 59 items. To analyze the data, which was collected through the questionnaire, a descriptive statistic has been used. Statistical Program for Social Sciences (SPSS) has been used as the data analysis tool. The aim of the data analysis was finding the impact of price on costumer decision-making process in three different categories of products.

\section{Results and Discussion}

As it already justified in literature review for generalizing the idea of this research, three categories are defined based on products life cycle, which are listed down. The results of three different categories of products will explain later.

- Short term products: all the products which have a lifetime less than one year

- Middle term products: all products those have life time between one year and five years

- Long term products: all the products those have life time more than five years

Customer's intention to buy for short term products: 99.1 percent of this survey's population responded to the questions related to short-term products while 0.9 percent of respondents did not answer for any reason. Table 1 shows the result of questionnaire regarding the short-term products. According to the table $1,25.8 \%$ of the respondents mentioned that they have no intention for buying or making any payment for short-term environmentally friendly products. In addition, $28.9 \%$ of them announced that they will pay up to $19 \%$ more and $21.5 \%$ of respondents expressed that they will pay up to 39 percent for purchasing green products in this category. $8.3 \%$ of respondents have been accepted to pay 40 to 59 percent more for buying environmental friendly products in comparison with none environmental friendly. The same number of respondents accepted to pay between 60 to 79 percent for green products and finally a minority of respondents $(6.3 \%)$ accepted to pay up to 100 percent for green products. Considering the table 1 , it is obvious that about $50 \%$ of respondents have intention to pay for short-term environmentally friendly product up to $40 \%$ percent. Therefore, the first hypothesis of this research has been proved. The statistics outcome demonstrates that in spite of the population of this study are categorized in the different levels of income (six categories) but the majority of correspondents were categorized as a great follower for short term Eco-friendly products and they point that there is a great possibility for companies to produce green (clean, safe, harmless, less energy consumption, less carbon dioxide emission, more saving in long time, and energy saving resource) products. On the other hand, almost a quarter of people have no interest for buying short term environmental friendly products which means that there are a significant number of people that they would not be interested to pay for short term environmental friendly products for any reason.

Table 1: Questionnaire result related to short-term products

\begin{tabular}{llll}
\hline & & Frequency & Percent \\
\hline Valid & No intention to buy & 90 & 25.8 \\
& $1-19 \%$ & 101 & 28.9 \\
& $20-39 \%$ & 75 & 21.5 \\
& $40-59 \%$ & 29 & 8.3 \\
& $60-79 \%$ & 29 & 8.3 \\
& $80-100 \%$ & 22 & 6.3 \\
& Total & 346 & 99.1 \\
Total & Missing & 3 & 0.9 \\
\hline
\end{tabular}


Customer's intention to buy for middle term products: 99.4 percent of respondents answered to the questions related to middle term products category while 0.6 percent of this survey's population did not answer for any reason. Table 2 shows the result of questionnaire regarding to the middle term products. According to the table 2, $16.3 \%$ of respondents mentioned that they had no intention for buying any middle term green products. About $20 \%$ mentioned that they have intention to pay up to $19 \%$, while $35 \%$ of them expressed that they will pay up to $39 \%$ for purchasing the green products. 16.3 percent of respondents also have been accepted to pay 40 to 59 percent more for buying environmental friendly products while 8.6 percent of respondents were agreed to pay between 60 to 79 percent for green products rather than normal products. Finally, a minority of respondents (2.6\%) accept to pay up to 100 percent for green products. It is notable that about $55 \%$ of respondents have intention to buy green products between 1 to 40 percent. This means the majority of respondents indicate that there is a great potential for companies to move toward green products. Therefore, the results also contribute to the second hypothesis of this study. According to this survey, there are a few people that they have no interest for buying the environmental friendly. However, there is still a capability for working on these few people to change their idea about environment and green products.

Table 2: Questionnaire result related to Middle term products

\begin{tabular}{llll}
\hline & & Frequency & Percent \\
\hline Valid & No intention to buy & 57 & 16.3 \\
& $1-19 \%$ & 72 & 20.6 \\
& $20-39 \%$ & 122 & 35.0 \\
& $40-59 \%$ & 57 & 16.3 \\
& $60-79 \%$ & 30 & 8.6 \\
& $80-100 \%$ & 9 & 2.6 \\
& Total & 347 & 99.4 \\
Total & Missing & 2 & 0.6 \\
\hline
\end{tabular}

Customer's intention to buy for long term products: $99.1 \%$ of respondents answered to this question while 0.9 percent of respondents did not answer for any reason. Table 3 shows the result of questionnaire regarding to the long-term green products. According to the table 3,12.9\% of respondents mentioned that they had no intention for buying or making any payment. About $19 \%$ of respondents had intention to pay up to $19 \%$ while about $18 \%$ of the respondents mentioned that they will accept to pay up to $39 \%$ for a long-term product. $27.7 \%$ also have been accepted to pay 40 to 59 percent more for buying environmentally friendly products in comparison with non-environmentally friendly in this category. Finally, a minority of respondents ( $8.3 \%$ ) accepted to pay up to 100 percent for green products. This result approves the third hypothesis and shows the number of people those accepted to pay up to 60 percent for long term environmentally products which is more than short and middle term products. Accordingly, as the statistic result exemplify, the majority of respondents were categorized as supporters of long-term green products and they specify that there is a great potential for companies to move toward producing Eco-friendly products. According to the results, there are only a few people that they have no interest for buying long-term environmental friendly products. However, the same with the other categories, there is still capability of working on these few people to change their attitude about buying environmental friendly and green products.

Table 3: Questionnaire result related to long-term products

\begin{tabular}{llll}
\hline & Frequency & Percent \\
\hline Valid & No intention to buy & 45 & 12.9 \\
& $1-19 \%$ & 68 & 19.5 \\
& $20-39 \%$ & 65 & 18.6 \\
& $40-59 \%$ & 96 & 27.5 \\
& $60-79 \%$ & 43 & 12.3 \\
& $80-100 \%$ & 29 & 8.3 \\
& Total & 346 & 99.1 \\
& Missing & 3 & 0.9 \\
Total & & 349 & 100.0 \\
\hline
\end{tabular}




\section{Conclusion}

According to the survey's result, the majority of respondents mentioned that they have intention for buying environmentally friendly in all three groups of products (short, middle and long term). It is also notable that the number of people who have no intention to buy is different among these three categories of products. For example, the number of people who have had no intention to buy the environmentally friendly products was more in short term in comparison to middle term and long term products. Another considerable subject is that the number of people those accept to pay more than fifty percent in long-term category is more than short term and middle term categories. It seems that respondents consider the extra payment for the long-term green products as investment, which will help them in saving and earn benefits in future. Considering the costumers' intention to buy and the amount that they accept to pay for all categories of environmentally friendly product, firms can allocate a specific budget for producing these kinds of products. They also may consider the additional production cost of green products for calculating the total price for consumers (i.e., production cost for considering eight dimensions of product quality in normal products plus additional cost of producing environmentally friendly equals to price of green products for customers). By understanding costumers' purchasing power regarding green products, it is easier to estimate the people's mindset and their purchasing power in different geographical area. In addition, since the population of this research was from postgraduate students and the majority of them will have good job positions, also they will belong to higher levels of society in the future; they have positive attitudes regarding buying green products. Therefore, there is a potential for generalizing the idea of buying green products for saving the environment, energy and resources by this population in the future. It is recommended that the authorities study the motivators that could persuade the customers who are not willing to buy green products, especially in short term products since the number of people who have no intention for buying environmentally friendly in this category is more than others.

\section{References}

Brucks, M., Valarie, A. Z. \& Gillian, N. (2000). Price and Brand Name as Indicators of Quality Dimensions for Consumer Durables. Journal of Academy of Marketing Science, 28(3), 359-374.

Coddington, W. (1990). It's no Fad: Environmentalism is now a Fact of Corporate Life. Marketing Magazine, 7.

Hume, S. (1991). Consumer double talk makes companies wary. Advertising Age, 62(46), 62-64.

Jacoby, J. \& Olson, C. J. (1977). Consumer Response to Price: An Attitudinal, Information-Processing Perspective. American Marketing Association, 2, 73-86.

Kalwani, M. U., Chi, K. Y., Rinne-Heikki, J. \& Sugita, Y. (1990). A Price Expectations Model of Customer Brand Choice. Journal of Marketing Research, 27(3), 251-262.

Kotchen, M. J. (2004). Impure public goods and the comparative statics of environmentally friendly consumption. Journal of Environmental Economics and Management, 49, 281-300.

Krejcie, R. V. \& Morgan, D. W. (1970). Determining sample size for research activities. Educational and Psychological Measurement, 30, 607-610.

Laroche, M., Bergeron, J. \& Barbaro-Forleo, G. (2001). Targeting consumers who are willing to pay more for environmentally friendly products. Journal of Consumer Marketing, 18(6), 503-520.

Murray, K. B. \& Schlacter, J. (1990). The Impact of Service versus Goods on Consumers' Assessment of Perceived Risk and Variability. Journal of Academic Marketing Science, 18(1), 51-65.

Nagy, S. (2004/2005). A környe zetbarát terméke kmar ketingje. Marketing \& Menedzsment, in Majlath, M. (2010). Can Individuals do anything for the Environment? - The Role of Perceived Consumer Effectiveness. Proceedings of FIKUSZ, 157-166.

Nash, B. (2002). Why Consumers Buy Green; why they do not. Barrier/Motivation Inventory, 3.

Paço, A. \& Raposo, M. (2009). Green segmentation: an application to the Portuguese consumer market. Marketing Intelligence \& Planning, 27(3), 364 - 379

Roberts, J. A. \& Bacon, D. R. (1997). Exploring the Subtle Relationship between Environmental Concern and Ecologically Conscious Consumer Behavior. Journal of Business Research, 40(1), 79-89.

Suchard, H. T. \& Polonski, M. (1991). A Theory of Environmental Buyer Behavior and its Validity: the Environmental Action-Behavior Model in Gilly, M.C. et al. (Eds), AMA Summer Educators' Conference Proceedings. American Marketing Association, IL(2), 187-201.

Zimmer, M. R., Stafford, T. F. \& Stafford, M. R. (1994). Green Issues: Dimensions of Environmental Concern. Journal of Business Research, 31(1), 63-74. 